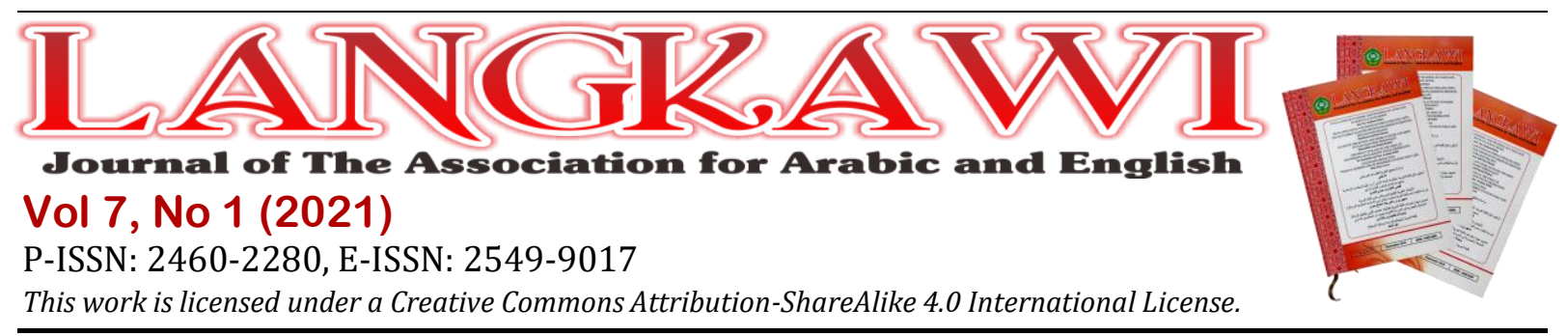

\title{
The Communicative Function of Non-Face Emoji "Folded Hands" in WhatsApp Interaction among Indonesians
}

\author{
Muhammad Muzakky1, Didin Nuruddin Hidayat ${ }^{2}$, Alek $^{3}$ \\ ${ }^{1}$ UIN Syarif Hidayatullah Jakata, Indonesia. E-mail: muhammad_muzakky19@mhs.uinjkt.ac.id \\ 2UIN Syarif Hidayatullah Jakata, Indonesia. E-mail: didin.nuruddin@uinjkt.ac.id \\ ${ }^{3}$ UIN Syarif Hidayatullah Jakata, Indonesia.E-mail: alek@uinjkt.ac.id
}

\section{ARTICLE INFO}

Keywords:

Computer-mediated discourse;

Emoji; Folded hands; WhatsApp

How to cite:

Muzakky, M., Hidayat, D. N., Alek, A. (2021). The

Communicative Function of Non-Face Emoji "Folded Hands" in WhatsApp Interaction among Indonesians. Langkawi: Journal of The Association for Arabic and English, 7(1), 95-105.

DOI:

http://dx.doi.org/ $\underline{10.31332 / \mathrm{lkw} . v 7 \mathrm{i1} .2374}$

History:

Received: 2020-12-26

Accepted: 2021-06-08

Published: 2021-06-24

\begin{abstract}
This study aimed to examine the communicative functions of the non-face "folded hands" emoji that Indonesians use in WhatsApp interactions. Using descriptive qualitative, the data were analysed through the social semiotic approach proposed by Lemke (1998), the interactional sociolinguistic theory (Gumperz, 1982), and speech act theory. The data were taken from the messages that occurred naturally in several WhatsApp groups. It was re-transcribed and translated in English based on the theory by Dresner and Herring (2010). The findings revealed some functions of the non-face "folded hands" emoji in online communication. At the end of an utterance, it emphasizes message tone, politeness, and soft interaction. Furthermore, rather than this emoji expresses an emotion such as face emoji does, it performs illocutionary forces in communication such as thanking, apologizing, and asking. It is also performed in situational interaction in which the relation of speaker and interlocutor has a formal relation such as teacher-students and leader-staffs. This empirical research added to computermediated discourse literature by analyzing the communicative function of folded hands emoji in written discourse. Practically, it might help users interpret the emoji as an abstract concept in the messages.
\end{abstract}

\section{Introduction}

Emojis are the advancement of what was called emoticons before. It has been broadly served in several online communication platforms like Instagram, WhatsApp, Twitter, Facebook, etc. An emoji such as GIFTs, electronic-emoticons, and other iconic graphic is frequently argued to help in clarifying the intended message, illocutionary force of written text and often add the meaning of the text (Dresner \& Herring, 2010; Thompson \& Filik, 2016; Herring \& Dainas, 2017; Haucsa et al., 2020). For instance, Lo (2008) found that the smiley face made the message look more positive than the message without a smiley face emoticon. Furthermore, emoji can reflect the phatic communication that can help construct social relationship correspondence (Aull, 2019).

Some researchers have proposed the functional aspect of emoji in computermediated discourse. Gibson et al. (2018) suggest that the "face-covering hand" emoji has communicative actions as laughter tokens in a message, and to emphasize the utterance was ironic. Another study revealed that emoji indicates purposive message 
tones such as emotion and attitude (Al Rashdi, 2018). Along with the lines, Riordan (2017) also suggests that emoji can make a message clear and reduce ambiguity; this is important in written communication. Table 1 is the functional emoji in online communication, adopted from Bai et al. (2019):

Table 1. Function of Emoji

\begin{tabular}{|c|c|c|c|}
\hline Emoji & Official Name & Meaning & Ambiguity \\
\hline & $\begin{array}{l}\text { Face with tears } \\
\text { of joy }\end{array}$ & $\begin{array}{l}\text { Something is funny } \\
\text { or pleasing Please }\end{array}$ & Loudly crying face \\
\hline & Sleepy face & Sleeping or tired & Crying face \\
\hline & $\begin{array}{l}\text { Face with Steam } \\
\text { From Nose }\end{array}$ & $\begin{array}{l}\text { Anger, content, } \\
\text { and irritation }\end{array}$ & Pride face \\
\hline & $\begin{array}{l}\text { Sad but relieved } \\
\text { Face }\end{array}$ & Anxiety or concern & Crying \\
\hline 6 & $\begin{array}{l}\text { Confounded face } \\
\text { Sad }\end{array}$ & Confused & Sad and frustrated \\
\hline$\cdots$ & Grimacing face & $\begin{array}{l}\text { Embarrassment, } \\
\text { awkwardness }\end{array}$ & $\begin{array}{l}\text { Mischievous } \\
\text { grimace }\end{array}$ \\
\hline
\end{tabular}

From Table 1, we know that one emoji can serve more than one meaning in communication. It depends on the contextual events. Novak et al. (2015) split emojis towards their sentiment distribution into positive, neutral, and negative. It was found that most of the emojis were positive, what is more, the popular ones. It can be said that people use more positive messages with emoji rather than negative or satirical emoji. The list of the functions is not well-comprehended because emoji is highly contextual. People may interpret the meaning differently (Darics, 2013). The human subjectivity to annotate the emoji seems to be explored, the meaning constructed by an emoji.

Due to emoji's function, people are often not aligned with what is strictly intended (Gibson et al., 2018). Thus, this study examines the linguistic understanding of non-face emoji folded hands ( $d$ ), named officially by Iemoji.com, that may have varied communicative functions in WhatsApp interaction among Indonesians. Furthermore, little is known of this emoji's function on how it is used in mediatedcomputer discourse, specifically WhatsApp in Indonesia.

WhatsApp is one of the popular digital platforms in smartphones that is to exchange instant messages. The user may deliver messages in text, images, audio, and video with other individuals or groups of people through the internet. Hootsuite's data, an online survey in 2019, shows that WhatsApp is ranked as the second most frequently used after Youtube in Indonesia. Indonesians regularly use it to communicate and exchange information effectively because it is faster to send and receive (Trisnani, 2017).

To make a grand claim of the emoji's function, the semiotic theories may help identify emoji meaning associated with the text. A social semiotic perspective 
elaborates with computer-media discourse will inform the written discourse of this study. Halliday and Hasan (1989) argued that semiotics includes the sign study in social communication. It is also described as the field of study to indicate the makingmeaning of symbols, gestures, contextual social, clothing, and actions used in a community (Jaipal, 2010). Hence, the social semiotic framework assumes that meaning-making cannot occur alone separately; it should include social situations and communication activities.

Lemke (1998) notes that during meaning-making, three functions are simultaneously constructed in communicative events. First, it presents events that describe the situation, experiences, relationships, and participants (who, where, why, under what conditions). Second, another function is the oriental function that refers to the meaning of statuses, participants' roles, and social connections between the text producer and the hearer/reader. The last function is the organizational function that refers to the relations between visual semiotic elements and the larger discourse circumstance.

Furthermore, to identify the language among the semiotic resource, the sociolinguistic framework needs to be used (Albawardi, 2018) to know the cultural value that affects the emoji's function. Interactional sociolinguistics (IS, hereafter) is a method to analyze the discourse. It is used to interpret the speaker intended in daily communication practice. As Gumperz (1982) stated, conversational infers into two verbal signs: the symbolic and indexical signs related to the context and the sign. Furthermore, IS analysis may be used to reduce ambiguity due to how communication actions cohere in line with the events' significance. Gumperz (1982) assumes that the conversational analysis developed the local or context-specific background knowledge that presuppositions in IS interpretive. Thus, to interpret what is communicatively intended, it is a must for the listener to go beyond the surface meaning to identify what is left unsaid.

Related studies have been conducted over the decades. Gibson et al. (2018) conducted a study to explore emoji's communication action in a mobile reading community in China. It concluded that through the conversation analysis, the emoji demonstrates the meaning of laugh in the message. Then, Al Rashdi (2018) implemented a study to examine the types of emojis frequently used by Omanis. The finding showed that emojis indicate a tone message that makes the message more emotional. It was supported by the resulting study by Zhou et al. (2017), who found that emoji helped mobile users to express their emotions better and supported the text in their messages to be more effective.

Nevertheless, despite the positive aspect of emoji, the study conducted by Thompson and Filik (2016) mentioned that some emoji were indicated sarcastic intent in communication, such as tongue face and wink face emoticon. Then, another work by Riordan (2017) revealed emojis indicating an essential aspect in communication text; it can reduce ambiguity. Related to gender and age, Jaeger et al. (2018) found that gender did not influence the interpretation of emoji. Both male and female participants can perform the same perspective of an emoji. It also engages young learners in comprehension of abstract concepts in communication to communicate thoughts, feelings, and positive responses through emoji (Fane, 2017). In the Indonesian context, Wahyuni and Budi (2018) conducted a study focusing on twitter that builds a 
computational model to classify the emoji to its language features: semantic and lexicon.

The present study has several gaps with the previous studies above. Here, it focused on WhatsApp interaction in Indonesia, a popular channel to interact. This study also pointed explicitly to non-face emoji "folded hands ( $\mathbb{A}$ )" exploring its functions during online communication. It was then combined the semiotic theory, the interactional sociolinguistic, and speech act theory to examine the various functions served by folded hands emoji in computer-mediated discourses. This research adds to computer-mediated discourse literature by offering the analysis of the communicative function of folded hands emoji in written discourse. Practically, it may help users on how to interpret this emoji as an abstract concept in messages.

\section{Method}

This study was executed with a case study to explore the phenomenon being discussed. The data of this study were picked from several WhatsApp groups in Indonesia. It consists of four WhatsApp groups. Three is lecturing groups where students-lecturer interact, and one is a teacher-community group where among teacher communicate. The groups were selected based on availability and the high frequency of "folded hands emoji" used. The groups consist of students-lecturer and teacher member-leader, so the group members' relationship tends to have formal and professional relationships. To anonymize the data, the names and others' identities were changed into an acronym.

In order to collect the data during the online interaction, a screenshot was used. At the beginning of the analysis, the result of the screenshot was described manually in pdf. The data presented was then translated into English. Furthermore, to show the emoji function's analytical description in each case, the theory from Dresner and Herring (2010) was implemented.

To get an in-depth analysis of how emoji used in written communication, the semiotic theory by Lemke (1998) was employed. In this stage, the messages were analyzed by looking at events that describe the situation, relationships, and participants (who, where, why, under what conditions the messages were sent). Then, the interactional sociolinguistics (IS) analysis (Gumperz, 1982) was developed to identify the function of emoji in certain events related to cultural and socio-context background. Lastly, to categorize emoji in several illocutionary forces and report the meaning of an utterance, speech act theory (SAT) by Brown and Yule (1983) was then used. To add, to produce the various functions performed by folded hands emoji, some expert judgments were also involved.

\section{Findings and Discussion}

From the four groups' WhatsApp interactions, the use of folded hands was identified. Since emoji is not fixed in meaning (Evans, 2017), this study found several different functions of folded hands emoji. It presents several illocutionary forces, such as apologizing, thanking, and requesting.

\subsection{Folded Hands Emoji and Communicative Function}

This study has argued to refer to the semiotic, IS, and speech act approaches on emoji analysis and examines the folded hands emoji's communicative purposes. There are three functions of folded hands emoji on its interpretation in a message. It is used 
to mean that the message delivered is polite, positive, and makes the soft fluidity in communication. Based on the data, the folded hands emoji is often written to indicate thanking expressions, apologizing. Then, the last indicates requesting something.

\subsubsection{Indicating Thanking}

Previous research found that emoji was used in positive messages, which also found in folded hands emoji. Below is two examples that emoji positively indicates to express thanking. Example 1 involves a short chatting taken from the English group lecturing. P1 (the lecturer) gives feedback in a book that the class already discussed in this interaction. Then, S1-S3 (the students) respond to him by saying thank you with a "folded hands" emoji at the end of the message.

Example 1:

$\rightarrow$ P1: Ini ebook mengenai translation yang kita td bicarakan

$\rightarrow$ S1: Alright, sir. Terima kasih_

$\rightarrow$ S2: Thank you sir $\lesssim$

$\rightarrow$ S3: thank you sir $\Omega$

Translation:

$\rightarrow$ P1: This is the e-book of the translation that we've discussed

$\rightarrow$ S1: Alright, sir. Thank you $\lesssim$

$\rightarrow$ S2: Thank you, sir. 2

$\rightarrow$ S3: Thank you, sir. \&

The students used the folded hands emoji to indicate their thanking expressions due to their acceptance from the lecturer. Then, this emoji interprets to give attitude clarification. Similarly, the next example 2 that takes from the thesis webinar WhatsApp group showed the committee (P1) gave the certificate for the participants (P1-P5) of the webinar. They use folded emoji to indicate that they say thank you deeply to the committee:

Example 2:

$\rightarrow$ P1: Berikut kami kirimkan Sertifikat Webinar

$\rightarrow$ P2: Syukron ketua®

$\rightarrow$ P3: Alhamdulillah saya sudah P.Idi, terima kasih $\Omega$

$\rightarrow$ P1: $\Omega$ Ditunggu lagi partisipasinya

Translation:

$\rightarrow$ P1: Here, we sent the certificate of Webinar.

$\rightarrow$ P2: Thank you, chief $\Omega$

$\rightarrow$ P3: Alhamdulillah, I have accepted it, Mr. Idi. Thank you』

$\rightarrow$ P1: $\Omega$ Alright, I wait for your next participation.

In line with example 1, the P2 and P3 used an emoji of folded hands to emphasize their thanking that the committee has already sent the certificate to facilitate the webinar they joined. In response, P1 (the committee) also used this emoji to respond to thanking.

The folded emoji hands may be used to convey thanks in which the speaker stresses politeness. As seen in example 1, as a result of what they get from the lecturer, 
the senders use the folded hands emoji to signify their thank-you gesture. Yus (2014) supported it, who claims this emoji interprets the 'clarification of attitude' to offer positive perceptions. Then, in example 2, the senders used a folded hand emoji to emphasize their gratitude. The use of emoji here is to replace politeness of face-to-face interaction, which is important in interpersonal interaction to represent respect of interlocutor face (Cruz, 2015). As also stated by Levinson (1983), politeness marks the reflection of someone respectful. In other words, the folded emoji has the function of expressing politeness in written communication.

\subsubsection{Indicating Apologizing}

One of the functions that emoji served is giving the tone in online communication. Here is example 3, taken from an English class group Whatsapp. The users try to give a low tone to the message by adding the emoji at the end of the utterance. The condition was that P1 (the class chief) informed their friends that the lecturer wanted to negotiate the lecturing schedule on that day. Then, P1-P4 (the classmates) cannot do one of the rescheduling options, folded hands emoji representing their sorry.

Example 3:

$\rightarrow \mathrm{P} 1$ : Kbm untuk thesis proposal lebih banyak dilakukan online tulis, apa bisa digeser ke jam 10 ?

$\rightarrow$ P2: Gak bisa jam $10 \Omega$

$\rightarrow$ P3: Gak bisa juga, msh ada jadwal daring dari sekolah $\bumpeq$

$\rightarrow$ P4: kalo jam 10 gak bisaa, masih kerja

Translation:

$\rightarrow$ P1: For the schedule of the thesis proposal, we conduct a google classroom, or can we reschedule for 10 o'clock?

$\rightarrow$ P2: I can't do for 10 o'clock

$\rightarrow$ P3: I also cannot do it because I have a teaching schedule from the school

$\rightarrow$ P4: If at 10 o'clock, I can't do it because I'm still at work $₫$

The students use the folded hands emoji to emphasize their apologizing expression humbly from the short message above. They cannot do the rescheduling options that are one of command by the lecturer. Instead of suggesting emotion, this emoji is conceived as a forced sign to respond to what has been textually stated.

Then it may be used for expressing apologies to others. People do this to make them feel intensely guilty for what they cannot do. The senders use the folded hands emoji from the short message in example 3 to humbly emphasize their apologizing gesture since they cannot make the offer. This emoji is conceived (textually) as a symbol of force rather than an expression of feeling (Dresner \& Herring, 2010). The senders use this emoji to produce positive impressions of the responder and perceived positive responsiveness (Coyle \& Carmichael, 2019). Moreover, the sender tries to make explicit feelings that cannot be articulated in words. They strategically and dynamically use it to attain communicative fluidity (Lim, 2015). In other words, the other function of folded emoji is to mark the positive responsiveness and build the communication flow in low tendency or softly. 


\subsubsection{Indicating Requesting}

As we know, in computer-mediated communication, non-verbal cues are lacking during the giving-sending message. Then, this emoji can replace body language in daily conversation. Below is the example 4 and 5 that use folded hands emoji to indicate begging something. As we see here, the conversation took from an English class group Whatsapp with the lecturer (P1), who ask for the students to contact the professor on the new schedule of his lecturing. Hence, the students (P2) respond to the command.

Example 4:

$\rightarrow$ P1: Mhn segera ada yg hubungi prof. ya $\Omega \Omega$

$\rightarrow$ P2: Sudah dihubungi sama gunawan bu $\Omega$

Translation:

$\rightarrow$ P1: Please, contact the professor soon. $\Delta \Omega$

$\rightarrow$ P2: Gunawan has already contacted, ma'am 0

The P1, above, used a triple folded hands emoji to emphasize that she would like to ask the students to contact the professor. The repetition of folded emoji might be described as an illocutionary force on the way P1 asks others to do something quickly. Another example of this term was found in the WhatsApp group chat where the English teacher in Depok was interacting as below:

Example 5:

$\rightarrow$ P1: Mohon infokan juga ke guru bhs Inggris di sekolah bpk/ibu yg tdk masuk grup ini $\Omega$

$\rightarrow$ P2: Done. Mom $\Omega$

$\rightarrow$ P3: Done ma'am $\lesssim$

$\rightarrow$ P4: Sudah ma'am $\bumpeq$

$\rightarrow$ P5: Done mom tati $\alpha$

Translation:

$\rightarrow$ P1: Please, inform the other English teacher at your school who didn't join this group $\Omega$

$\rightarrow$ P2: Done, Mom

$\rightarrow$ P3: Done ma'am $\Omega$

$\rightarrow$ P4: I've done, ma'am $\lesssim$

P5: Done, Mrs. Tati $\lesssim$

As we can see, the P1 (the committee of English teachers at Depok) informed the other teachers in the WhatsApp group, folded hands representing that she humbly asked to inform the other teacher outside the group to do something related to the announcement. Then, the P1-P5 conveyed that the task had already been fulfilled.

From the data, it is argued that individuals use folded emoji often to request something humbly. As presented in example 4, the speakers used triple folded emoji hands to describe an illocutionary force that asks others to do something (Dresner \& Herring, 2010). In line with this, example 5 showed that the sender tells the responders 
in the WhatsApp group with folded hands that she humbly asks them to do something. In examples 4 and 5, both the sender and respondent use emoji to produce positive interaction and help them express their messages more effectively (Cruz, 2015; Zhou et al., 2017). Kaye et al. (2017) supported it, who said that the emoji could express an emotional tone often lost in written communication. In addition, such love emoji does, this emoji intends to convey a very positive sentiment (Jaeger et al., 2018).

To sum up, in the absence of face-to-face interaction, the sender used the folded emoji to express the message tone and build the positive interaction among the speaker and interlocutor. To add, based on the data which the people lived in the educational area, it can be said that the folded emoji often used in the formal chat that the relationship between the users and the interlocutor has the formal relation such as teacher-students, leader-staff, and chief-member.

\subsection{Folded Hands Emoji and Cultural Meaning}

The use of emoji is structured by a combination of social norm and cultural context (Bai et al., 2019), which is influenced by some factors: historical culture, living background, and language community of the users. They believe that many natural languages have developed from a shared need to connect through cultural symbols and experiences. Moreover, to understand the social significance of language usage, it is important to know the basic structural properties of verbal interaction (Levinson, 1983).

Folded hands emoji is a critical part of text-based media communication that takes body language in face-to-face interaction. The symbol of this emoji " $₫$ " refers to the meaning of body language that Indonesian used to stress politeness. Furthermore, this emoji has meaning independently without the need for the text (Khandekar et al., 2019). However, Zhou et al. (2017) claimed that emoji must be combined with the text to form a full meaning to help in improving the text's clarity and credibility. To sum up, cultural background plays an important role in giving the meaning of emoji. In the current case, Indonesian used this emoji to represent nonverbal language such as "folded hand," which in daily conversation is categorized as politeness and respect. As a result, they also use this emoji to indicate something to do politely in text-media communication.

Concerning the social norm, this emoji is frequently used in some acts that are threatening social harmony and therefore involving softening of linguistic strategies (Fitriah \& Hidayat, 2018; Geyer, 2008). Linguistic politeness is a standard verbal practice within society. In addition, the folded emoji used is affected by two main factors such as interpersonal relationships and contextual information (Bai et al., 2019), where based on the data, the interpersonal relationship of sender and responder has a formal social status such as teacher and students, leader and staff. Related to the contextual information, it is mostly in a formal situation such as lecturing and office. In other words, folded emoji is used in professional online communication. Sociolinguistics also put the role on this emoji used. Indonesian try to build a harmonious relationship with others who have different social statuses by using this emoji in their online communication. To add, previous studies related to emoji used interaction, none of the researchers found this emoji " $\wedge$ " used as thanking, apologizing, and requesting politely, only Indonesians put its value. It may be caused 
of different cultural backgrounds as well as social norm rules. This research implies that the folded hands emoji adds the positive message tone which help emoji users in corresponding good relationship in written communication. Indonesian often used it to replace the cultural gesture while thanking, apologizing, and requesting in face to face interaction. Based on the data, people, who have the formal, frequently promote this emoji in online communication.

\section{Conclusion}

Through WhatsApp interaction analysis, the folded hands emoji has several communicative functions. It is used to emphasize message tone because, in written interaction, the emotion is often lost. Then, it also indicates politeness in the message. Last, the emoji was used to build soft interaction and to perceive positive responsiveness. Therefore, rather than this emoji expresses an emotion such as face emoji, it performs illocutionary force in communication, such as thanking, apologizing, and requesting used at the end of an utterance. Because emoji is highly contextual, it is open up for future research to interview emoji users to explore their specific purposes in using emoji. It is also interesting if gender issues as sociolinguistics are inserted into this study whether male or female often use this emoji.

\section{References}

Al Rashdi, F. (2018). Functions of emojis in WhatsApp interaction among Omanis. Discourse, Context and Media, 26, 117-126. https://doi.org/10.1016/j.dcm.2018.07.001

Albawardi, A. (2018). The translingual digital practices of Saudi females on WhatsApp. Discourse, Context and Media, 25, 68-77. https://doi.org/10.1016/j.dcm.2018.03.009

Aull, B. (2019). A study of phatic emoji use in WhatsApp communication. Internet Pragmatics, 2(2), 206-232. https://doi.org/10.1075/ip.00029.aul

Bai, Q., Dan, Q., Mu, Z., \& Yang, M. (2019). A systematic review of emoji: Current research and future perspectives. Frontiers in Psychology, 10(October). https://doi.org/10.3389/fpsyg.2019.02221

Brown, G., \& Yule, G. (1983). Discourse Analysis: Cambridge Textbooks in Linguistics. Cambridge University Press.

Coyle, M. A., \& Carmichael, C. L. (2019). Perceived responsiveness in text messaging: The role of emoji use. Computers in Human Behavior, 99(April), 181-189. https://doi.org/10.1016/j.chb.2019.05.023

Cruz, M. P. (2015). Pragmatics and Discourse Analysis. The Encyclopedia of Applied Linguistics, (August), 1-6. https://doi.org/10.1002/9781405198431.wbeal1463

Darics, E. (2013). Non-verbal signalling in digital discourse: The case of letter repetition. Discourse Context Media, 2(3), 141-148.

Dresner, E., \& Herring, S. C. (2010). Functions of the nonverbal in CMC: Emoticons and illocutionary force. Communication Theory, 20(3), 249-268. https://doi.org/10.1111/j.1468-2885.2010.01362.x

Evans, V. (2017). The emoji code: How smiley faces, love hearts and thumbs up are changing the way we communicate. Michael O'Mara.

Fane, J. (2017). Using emoji as a tool to support child wellbeing from a strengths-based 
approach. Learning Communities: International Journal of Learning in Social Contexts, 21, 96-107. https:/ / doi.org/10.18793/lcj2017.21.08

Fitriah, F., \& Hidayat, D. N. (2018). Politeness: Cultural dimensions of linguistic choice. Indonesian Journal of English Education, 5(1), 26-34.

Geyer, N. (2008). Discourse and Politeness: Ambivalent Face in Japanese. New York: Bloomsbury Publishing.

Gibson, W., Huang, P., \& Yu, Q. (2018). Emoji and communicative action: The semiotics, sequence and gestural actions of 'face covering hand.' Discourse, Context and Media, 26, 91-99. https:// doi.org/10.1016/j.dcm.2018.05.005

Gumperz, J. (1982). Discourse Strategies. Cambridge University Press.

Halliday, M. A. ., \& Hasan, R. (1989). (Language Education) M. A. K. Halliday, Ruqaiya Hasan, Frances Christie - Language, Context, and Text_Aspects of Language in a SocialSemiotic Perspective -Oxford University Press, USA (1989).pdf (p. 71). p. 71.

Haucsa, G. M., Marzuki, A. G., Alek, A., \& Hidayat, D. N. (2020). Illocutionary Speech Acts analysis in Tom Cruise's interview. Academic Journal Perspective: Education, Language, and Literature, 8(1), 11-19.

https://doi.org/10.33603/perspective.v8i1.3304

Herring, S., \& Dainas, A. (2017). "Nice Picture Comment!" Graphicons in Facebook Comment Threads. Proceedings of the 50th Hawaii International Conference on System Sciences (2017), (January). https:/ / doi.org/10.24251/hicss.2017.264

Jaeger, S. R., Xia, Y., Lee, P. Y., Hunter, D. C., Beresford, M. K., \& Ares, G. (2018). Emoji questionnaires can be used with a range of population segments: Findings relating to age, gender and frequency of emoji/emoticon use. Food Quality and Preference, 68, 397-410. https://doi.org/10.1016/j.foodqual.2017.12.011

Jaipal, K. (2010). Meaning making through multiple modalities in a biology classroom: A multimodal semiotics discourse analysis. Science Education, 94(1), 48-72. https://doi.org/10.1002/sce.20359

Khandekar, S., Ryu, C. W., Higgs, J., Talton, J. O., Bian, Y., \& Kumar, R. (2019). OPICO: A study of emoji-first communication in a mobile social app. The Web Conference 2019 - Companion of the World Wide Web Conference, WWW 2019, 18(June), 450-458. https://doi.org/10.1145/3308560.3316547

Lemke, J. (1998). Multiplying meaning: Visual and verbal semiotics in scientific text. Reading Science: Critical and Functional Perspectives on Discourses of Science, 87-113. https://doi.org/10.4324/9780203982327-17

Levinson, S. C. (1983). Pragmatics. Cambridge University Press.

Lim, S. S. (2015). On stickers and communicative fluidity in social media. Social Media and Society, 1(1), 1-3. https:/ / doi.org/10.1177/2056305115578137

Lo, S. (2008). The nonverbal communication functions of emoticons in computermediated communication. CyberPsychology \& Behavior, 11(5), 595-597. https://doi.org/10.1089/cpb.2007.0132

Novak, P. K., Smailović, J., Sluban, B., \& Mozetič, I. (2015). Sentiment of emojis. PLoS ONE, 10(12), 1-21. https:/ / doi.org/10.1371/journal.pone.0144296

Riordan, M. A. (2017). The communicative role of non-face emojis: Affect and disambiguation. Computers in Human Behavior, 76, 75-86.

https://doi.org/10.1016/j.chb.2017.07.009

Thompson, D., \& Filik, R. (2016). Sarcasm in written communication: Emoticons are 
Muhammad Muzakky, Didin Nuruddin Hidayat, Alek: The Communicative Function of Non-Face Emoji "Folded Hands" in WhatsApp Interaction among Indonesians

efficient markers of intention. Journal of Computer-Mediated Communication, 21(2), 105-120. https://doi.org/10.1111/jcc4.12156

Trisnani, T. (2017). Pemanfaatan WhatsApp sebagai media komunikasi dan kepuasan dalam penyampaian pesan di kalangan tokoh masyarakat. Jurnal Komunika: Jurnal Komunikasi, Media Dan Informatika, 6(3), 1-12.

https://doi.org/10.31504/komunika.v6i3.1227

Wahyuni, R., \& Budi, I. (2018). Combining Linguistic, Semantic and Lexicon Feature for Emoji Classification in Twitter Dataset. Procedia Computer Science, 135, 194-201. https://doi.org/10.1016/j.procs.2018.08.166

Zhou, R., Hentschel, J., \& Kumar, N. (2017). Goodbye text, hello emoji: Mobile communication on WeChat in China. Conference on Human Factors in Computing Systems - Proceedings, 2017-May, 748-759.

https://doi.org/10.1145/3025453.3025800 